\title{
La necesidad del otro en el cuento El antropófago de Pablo Palacio
}

\section{The need of the other in the story El antropófago by Pablo Palacio.}

DOI: https://doi.org/10.29166/tyc.v1i22.3003

\section{Fernando Vinces Díaz}

Comunicador Social con énfasis en Educomunicación, arte y cultura por la Universidad Central del Ecuador. Especialista Superior en Educación y Nuevas Tecnologías de la Información y Comunicación por la Universidad Andina Simón Bolívar. Ha colaborado con Ineval en la elaboración de reactivos para las pruebas Ser Maestro y Ser bachiller.

Correo: fernando.vinces@outlook.es

\section{Resumen}

Esta investigación aborda la dicotomía civilización-barbarie como un discurso que se plasmó en el cuento El antropófago de Pablo Palacio gracias a las transformaciones e intromisión de la modernidad en el Ecuador de inicios del siglo XX. A través del análisis discursivo se develará el inconsciente del texto para dar respuesta a la siguiente interrogante: ¿es la exclusión una estrategia civilizatoria o también la practica la barbarie?

Palabras clave: discurso, civilización-barbarie, nosotros-otro, exclusión, imaginarios

\section{Abstract}

This research addresses the civilization-barbarism dichotomy as a discourse that was embodied in the story "El antropófago " by Pablo Palacio due to the transformations and the interference of modernity in Ecuador at the beginning of the 20th century. Through a discursive analysis, the unconscious of the text will be revealed to answer the following question: is exclusion a civilizing strategy or is it also practiced by barbarism?

Keywords:discourse / civilization - barbarism / us - the other / exclusion / imaginaries. 


\section{Introducción}

La dicotomía nosotros-otro ha estado presente en algunos estudios de Europa, pero con matices; algunos investigadores colocaron la mira sobre los problemas de la otredad desde perspectivas ligadas a lo étnico, lo extranjero, la marginalidad, la moral y la antonimia entre campo y ciudad, y permitieron comprender que, en primera instancia, el dilema de la exclusión en la realidad europea posee varias aristas que coinciden en que el otro siempre es el relegado, el perseguido, el no-normal, pero también, el mal necesario. Así, por ejemplo, la obra de Nuzzo (2003) estudia el pensamiento de Giambattista Vico, renacentista, para concluir que la forma de ver la historia de este filósofo parte del reconocimiento de un elemento natural que ha sido superado en varias fases, pero que siempre está presente, y que, sin él, la Humanidad no habría podido alcanzar su estado de racionalidad. A esto le llamó barbarie. Esta investigación es el mejor punto de partida para estudiar la dicotomía nosotros-otro y cómo se ha visto en Europa, puesto que Friese (2004), más adelante, corroboró que Europa se ha construido como una identidad única, unida bajo preceptos como el cristianismo, la razón y la guerra, pero que, en realidad, siempre fue descentrada, con identidades y otredades que intentó negar pero que en la modernidad y con la aceleración de los intercambios humanos se pusieron en evidencia, por lo que el continente atraviesa una crisis de identidad. Con estos análisis quedó claro que el humano occidental se identificó desde el bárbaro, la otredad, lo que atrajo a Rea (2006) y Re (2012) para analizar el fenómeno migratorio y deducir que son, precisamente, los extranjeros quienes han contribuido a construir la autoconcepción europea, puesto que quien llega de otro lugar es el no-europeo, cuyos rasgos se conciben como alejados de lo civilizatorio $\mathrm{y}$, de esta manera, ayudan a construirlo. Sin embargo, estos no fueron los únicos aspectos en los que se evidencia la otredad del continente, ya que Almazán (2016) y Cuadrada (2015) la observaron en la marginalidad referente al campo y lo excluido, es decir, no es solo el extranjero quien constituye el otro en Europa. Estas investigaciones son curiosas, porque demuestran que el orden civilizatorio occidental parte de la expulsión del otro, lo que plantea una seria pregunta: ¿es solo en estos espacios, lo extranjero, lo marginal y lo rural, que se construye la identidad occidental? Parrilla (2007) es quien respondió esta duda, ya que explicó que el otro, en el orden civilizatorio, se expresa en cualquier persona o grupo al que se le atribuya el epíteto de animal o salvaje, lo que significa que lo no racional es la contradicción del nosotros.

Las reflexiones e investigaciones alrededor de esta temática tuvieron también especial relevancia en América Latina, pero con una curiosa variante, $y$ es que, al haber estado colonizada por europeos, la región fue, precisamente, el lado excluido, ese otro-animal del que habló Parrilla, así que los intentos de los pensadores se enfocaron en reestructurar esta asociación de lo latinoamericano con la otredad europea. Por tal motivo, uno de los primeros intentos por reflexionar sobre el tema se dio cuando se conformaban los Estados-nación, pues la genera- 
ción de una patria única planteaba la duda sobre la identidad de la región. Aquí, Sarmiento (1845) tuvo especial relevancia, ya que sus ideas derivaron en una América Latina que buscó aprender la cultura europea, asimilarla como paradigma de desarrollo y luz. Ante esto, se gestaron perspectivas acerca de si la región debía imitar a Europa o si el camino estaba en la recuperación de lo bárbaro, adjetivo otorgado por los colonizadores a los pueblos sometidos en América, el otro de Europa (Todorov, 1998). Fernández Retamar (2004) es uno de quienes se destacan en este dilema, pues propuso que la identidad de la región debía ser la del caníbal, la antropofagia, no la imitación de Europa. Estos constituyeron intentos filosóficos y ensayísticos que propiciaron un debate de décadas. Rodríguez Jiménez (2014) aportó desde una investigación sobre la propuesta de Martí y concluyó que, si bien es cierto que el pensamiento de Sarmiento fue preponderante, en la región también se ha defendido, de diversas maneras, la perspectiva de que la relación entre lo humano y lo natural, lejos de ser rechazada debe ser asimilada y colocada como bandera. Este debate se plasmó en las obras literarias, pues, generalmente, contaron historias con la balanza inclinada hacia el lado de Sarmiento, algo que se aprecia gracias al estudio de Ozoukouo (2013), quien indagó en algunos relatos latinoamericanos y descubrió que esta dicotomía se encuentra plasmada en los personajes campesinos y urbanos, siendo los primeros quienes quedan relegados.

Por otro lado, Santamarina (2005) desarrolló un completo estudio sobre la dominación mexica y su trabajo permitió comprender que la imposición ideológica del Estado imperial azteca se derivó, pre- cisamente, de la exclusión del otro-conquistado, lo cual sucedía de dos maneras: la primera, mediante los sacrificios de prisioneros de guerra, que posicionaban el discurso religioso de los vencedores mexicas como el imperante, en el cual se sostenía que ellos debían realizar estos actos para apaciguar con sangre la furia divina, lo que solo funcionaba debido a la imposición religiosa, que actúa como la segunda manera de exclusión, ya que el dios mexica Huitzilopochtli fue sobrepuesto al Quetzalcoatl tolteca que, evidentemente, quedaba relegado y excluido, generando un nuevo culto que correspondía a la cultura dominante. Asimismo, el otro gran imperio de América, los incas, se caracterizó por la exclusión de los conquistados, aunque con menos ferocidad, debido a que los conquistadores permitieron a los pueblos sometidos que mantuvieran ciertas costumbres y creencias, pero debían adoptar el culto al sol como religión hegemónica, además del quechua (Ayala Mora, 2008). Esto demostró que la exclusión con el fin de imposición estuvo presente desde la etapa precolombina y, por lo tanto, aporta ideas ligadas a lo otro desde una perspectiva holística y no únicamente colonial. En todo caso, es conveniente aclarar que, en rigor, la civilización y la barbarie son la forma de ver la exclusión desde el discurso civilizatorio europeo, sin embargo, se enmarcan en la generación de la otredad como estrategia identitaria y de dominación.

Con esta influencia en la región, en Ecuador se desarrollaron también varios estudios, como el de González (1996), en el que se observa que la instauración de la modernidad es la causa de que aparezcan las ciudades, lo que genera la exclusión hacia lo campesino, una realidad muy notoria en los prime- 
ros pasos de la república. Esta preocupación se trasladó al campo de las representaciones artísticas y aquí destacan Martín (2010) y Vega (2014), en cuyos trabajos se aprecia que el otro es representado en asociación a lo marginal o al campo, pero siempre como el excluido. En el campo ensayístico, Grijalva (1997) es quizás quien presenta un panorama amplio al estudiar la obra Las Catilinarias del escritor ambateño Juan Montalvo, lo que trasladó la mirada hacia las letras y la dicotomía civilización-barbarie, en donde Rodríguez Albán (2006) adquiere vital importancia debido a su análisis de la literatura ecuatoriana y su conclusión acerca de la identificación entre civilización-barbarie y razón-sin razón, urbano-rural o bueno-malo. Quizás lo indispensable de esta autora radica en que demostró que la literatura es un producto que denota la influencia de la modernidad en Ecuador, pues en las letras, necesariamente, se plasma la realidad social. Los trabajos de Palacios (2002), Holst (1998) y Cevallos (2006) se inscriben en la misma temática.

Con base en esta información, se encontró un vacío en los estudios ecuatorianos acerca de la dicotomía civilizaciónbarbarie, el cual radica en que las investigaciones han tendido a ver la exclusión derivada de la modernidad mayormente desde el punto de vista étnico, siendo poco explorado el dilema de la exclusión comprendiendo al otro no solo como el resultado de la imposición de la identidad europea, sino como acto de autoconcepción humana, lo que significa que el interés de esta investigación fue demostrar que el cuento El antropófago de Pablo Palacio es un objeto discursivo que permite entender la exclusión desde una mirada que va más allá de lo racial o europeo, y se centra en la identidad misma. Por tal motivo, se buscó develar las construcciones discursivas, por lo tanto, comunicacionales, acerca de civilización y barbarie presentes en el texto El antropófago de Pablo Palacio, para lo cual se recurrió a conceptualizar los imaginarios, el poder, la hegemonía y el otro, para establecer la base teórica con la que se comprendió al texto más allá de un análisis literario.

Esto permitió determinar tres hipótesis que se resumen en que el canibalismo explícito del antropófago, por el que lo encarcelan, devela cómo mediante la exclusión de lo no-normal la sociedad entiende qué es lo normal y logra así crear la cultura dominante; además, Pablo $\mathrm{Pa}$ lacio realiza un giro del punto de vista, coloca al bárbaro como el "Nosotros”, y, con esto, el cuento muestra un bárbaro aplicando las mismas estrategias de exclusión que el civilizado, denotando que el dilema del otro no es una cuestión únicamente civilizatoria, sino de la conformación social; por último, la antropofagia, como expresión de las luchas de poder, muestra que no puede existir sociedad sin que un grupo intente devorar al otro. Para demostrarlas, se utilizó el método del cuadrado ideológico propuesto por Van Dijk (2005), que permitió categorizar el corpus de enunciados desde el punto de vista del bárbaro, con lo que se concluyó que el dilema de la civilización y la barbarie es, ciertamente, una estrategia de exclusión para formar la identidad europea pero que se usa también desde el imaginario del excluido, en un juego en el que los roles cambian constantemente y la civilización, razón, normalidad, como quiera llamarse, es la excluyente, pero también la excluida. 
La avidez de la identidad: el otro, el poder y el imaginario

La investigación partió de los imaginarios sociales, ideología, hegemonía, subalternidad y la dicotomía nosotrosotro como categorías de análisis que permitieron demostrar las hipótesis. Esto porque la dualidad civilización-barbarie es un imaginario que ha formado ideologías, que, a su vez, se han vuelto hegemónicas y subalternas.

Sin caer en disertaciones existenciales, es conveniente describir que el humano es una especie que posee conciencia de su ser y, por tal motivo, requiere responder ciertas preguntas que lleva a cuestas (Nietzsche, 1970), lo que significa que se encuentra en la permanente búsqueda de certidumbres, pero, debido a que no puede encontrarlas en un universo azaroso, está obligado a crearlas. Aquí es cuando los imaginarios cobran sentido, ya que son imágenes mentales, conceptos, ideas (racionales o no) que permiten construir cierto piso estable para la conciencia (Castoriadis, 2007), y con las cuales inician las relaciones sociales. Estas abstracciones empiezan de forma individual como un imaginario radical (Silva, 2006), pero luego se relacionan con otras en el seno de la vida gregaria y entran en un conflicto sin tregua por su afianzamiento, con la única intención de institucionalizarse para perpetuarse (imaginarios sociales). Esto significa que los imaginarios son indispensables para la conformación de la identidad, puesto que son "ideaciones socialmente compartidas de significancia práctica del mundo, destinadas al otorgamiento de sentido existencial" (Baeza, 2011, p. 33). Sin embargo, por sí mismos no pueden funcionar, requieren aglome- rarse, encontrar enlaces comunes con otros, lo que lleva a construir ideologías; es decir que, de acuerdo con la forma en que una persona perciba el mundo se reunirá con quienes comparten sus ideas, lo que, necesariamente, construirá agrupaciones que establecen ciertos cánones de comportamiento, esquemas mentales que plantean reglas tácitas que determinado grupo debe seguir para defender sus concepciones. A esto se conoce como la ideología (Van Dijk, 2003).

Este proceso es el que genera identidades que se basan en la exclusión, puesto que una ideología, al plantear cánones de comportamiento y lo que es aceptado, requiere también crear lo no aceptado, es decir: "somos el grupo A porque imaginamos el mundo de esta manera y tenemos razón, mientras que los no-A no pertenecen a este grupo, o sea que no tienen la razón porque no piensan como nosotros". Esto lleva a pensar en una intrincada trama de luchas imaginarias que termina con la asimilación de las ideas del grupo A o el no-A como verdaderas y, por lo tanto, las del grupo rechazado como falsas.

El proceso de construcción de identidad a partir de imaginarios e ideologías solo es posible si se pone en juego el poder, entendido como una voluntad de afianzamiento, lo que significa que toda relación social es, en sí misma, una lucha de poder, ya que esta voluntad de afianzamiento es innata en los seres con conciencia y en búsqueda de certezas (Nietzsche, 1970). La importancia de esta aseveración radica en que la certeza social solo existe si determinados imaginarios se han asimilado en la población, es decir que no cabe que cada individuo piense y actúe en el mundo conforme a un relativismo que solo afianza la incertidumbre. 
Con este panorama, deducir que la exclusión es una estrategia necesaria para formar la identidad es casi axiomático, no solo porque el imaginario que se agrupa en las ideologías se sirva de ella para funcionar, sino porque las relaciones de poder se fundamentan, precisamente, en lo rechazado, fenómeno que sucede debido a que el ejercicio del poder requiere crear certezas y solo lo puede hacer negando su contradicción (Foucault, 1980), mas no eliminándola. Por tal motivo, una aseveración concebida como aceptada o verdadera enmascara su contrario, así funciona el poder, que constituye la energía de impulso para colocar las ideologías en contraposición. Así que el enfrentamiento tácito que sucede en el seno de la sociedad se da no solo en el ámbito político, sino también económico, cultural y, sobre todo, imaginario.

En todo caso, saber qué elementos se inmiscuyen en las bregas simbólicas sociales no es suficiente para comprender la civilización y la barbarie, puesto que, en el imaginario occidental, estas ideas se han grabado de generación en generación, convirtiéndose en una suerte de verdades absolutas que, pese a los esfuerzos de los colectivos sociales, no han sido, en el discurso, refutadas; es decir que esta dicotomía tiene plena vigencia. Pero, si lo que se concibe como verdad es solo una construcción del pensamiento y no la realidad misma, entonces queda por averiguar por qué tiene tanta vigencia.

Para explorar la utilidad de este discurso, Gramsci (1984) propone una explicación basada en la hegemonía. Esta categoría de análisis consiste en que en el proceso de lucha ideológica e imaginaria descrito solo forma la verdad si y solo si la ideología vencedora se ha asimilado en el pensamiento, de tal forma que no solo es aceptada por la gente sino también defendida. Así que este momento, cuando determinada forma de pensar se instala en la mente, constituye una táctica en la que las ideologías ya son defendidas en actos conscientes.

Para conseguir esto, las verdades imaginarias requieren implantarse en el acervo intelectual y cultural de forma más o menos inconsciente, lo que sucede cuando una de las representaciones sociales que circulan es absorbida y, por ende, defendida.

La hegemonía, entonces, sucede solo cuando ya se han construido esas verdades, es decir que la verdad solo lo es cuando es hegemónica, de lo contrario, es negada, por lo tanto, aquí es donde surge la dicotomía de la civilización y la barbarie, puesto que una de ellas (civilización) es hegemónica y, por ende, la barbarie es relegada, pero no desaparecida. Esa concepción, ese imaginario o ideología que fue enmascarada por otra en las luchas de poder se convertirá en lo que Gramsci llamó la subalternidad.

La subalternidad es aquello que no se absorbió como verdad irrefutable, pero es claro que sí lo hizo, solo que debajo del mantel. Según Modonesi (2010), la subalternidad sucede cuando se despoja de la calidad subjetiva a las personas debido a que ahora ya no piensan por sí mismas sino conforme a una representación hegemónica, pero Gramssci (1984) permite comprender que el dilema de lo subalterno no solo significa dominación sino también la condición de existencia de una necesidad de liberación por parte del subordinado. Es decir que lo hegemónico y lo subalterno equivaldrían a la civilización y la barbarie respectivamente en el orden occidental, pero la barbarie trata de liberarse, como se develará más adelante en 
esta investigación. El mismo Modonesi (2010) sostuvo que lo sometido intenta liberarse, utiliza estrategias de lucha que terminan jugando en el mismo campo y con las mismas reglas que lo hegemónico, lo que se podría traducir en que lo subalterno se convierte en una fuerza contrahegemónica que intenta, de igual modo, establecer verdades, posicionar e institucionalizar sus imaginarios e ideología a través de las luchas de poder.

Este proceso que sigue un imaginario hasta volverse hegemónico lleva como constante la contradicción que debe ser excluida, lo que significa que el dilema del otro es, y siempre ha sido, el dilema del yo. Esta idea parece apoyada por Lacan (1996) con su explicación sobre el estadio del espejo, en la que se describe que la identidad, desde el punto de vista psicológico, empieza cuando el niño reconoce que su madre es otro cuerpo tras mirarse en el espejo y ser consciente de sí mismo. En otras palabras, el autorreconocimiento sucede solo si se niega al otro. Entonces, es importante comprender qué es el otro.

Como ya se ha establecido, identificarse significa, inexorablemente, excluir, solo que, a veces, esa exclusión proviene de los grupos de poder y, entonces, es más notoria. La idea de que debe existir un otro no es descabellada y, de hecho, es lógica, pues el otro es un punto de refracción en el que se contraponen "nuestros" valores con los "suyos" (Eco, 2011). La necesidad de formar un contrario, por lo tanto, es inevitable.

Aunque diversos pensadores han tratado de abordar la temática del otro desde varias aristas, como el extranjero, el bárbaro, el salvaje, el animal, la mentira, lo falso, y un largo etcétera, todo se resume en el concepto del otro, que, a su vez, es el nosotros. Según Eco, ese otro, el enemigo, contra el que se contraponen nuestros valores e imaginarios, es una construcción, no existe en estado natural.

Esto significa que el otro es un imaginario que se ha vuelto hegemónico, pues, como hemos visto, la forma de construir esos cimientos sociales que son las certezas, las verdades, es a través de la imagen mental que se materializa en acciones y que crea estructuras sociales determinadas.

En definitiva, la dicotomía nosotros-otro y, por ende, la civilización y la barbarie constituyen un imaginario hegemónico sobre el que se ha construido la razón occidental y que ha funcionado gracias a que ha permitido excluir a los otros para afianzar las ideologías europeas (Todorov, 1998), pero esto, precisamente, ha generado la necesidad de liberación y autoidentificación del otro, que busca comportarse desde el nosotros.

\section{La vanguardia ecuatoriana y la intromisión de la modernidad}

La obra de Pablo Palacio se inscribe, sobre todo, en la segunda década del siglo XX, momento de grandes transformaciones para el Ecuador. En primer lugar, apenas iniciando el siglo, el país aplicaba las reformas de la Revolución liberal, que significó la modernización de las instituciones estatales, siguiendo el ejemplo de Francia y Estados Unidos, de hecho, con la misma intención: industrializar y capitalizar el Estado-nación ecuatoriano que, desde 1830 , no encontró una identidad debido a los conflictos por el poder político entre conservadores y liberales.

Reformas como la eliminación del tributo indígena, derecho a la educación 
para los ciudadanos y el laicismo favorecieron a la burguesía agroexportadora que con el boom cacaotero de finales del siglo XIX se convirtió en la principal fuerza económica del país, lo que sirvió para capitalizar las relaciones sociales, promoviendo una relación laboral totalmente asimétrica (Ayala Mora, 2008). Este problema detonó cuando, producto de la I Guerra Mundial, el cacao dejó de venderse en Europa y, por ende, provocó una crisis desde 1914 cuyo peso fue arrojado sobre los trabajadores, quienes tuvieron que resistir el congelamiento de sus pagos, así como la devaluación constante de la moneda debido al libertinaje que los gobiernos plutocráticos favorecieron para la burguesía y banca costeñas. Como resultado, el 15 de noviembre de 1922, los obreros de Guayaquil lideraron un levantamiento que fue reprimido duramente por el gobierno de Tamayo y que terminó con varias muertes a manos del Estado.

En medio de esta capitalización, la liberación de algunos indígenas del trabajo en relación de servidumbre en las haciendas serranas significó nueva mano de obra para las grandes plantaciones cacaoteras (Acosta, 2006), lo que ocasionó una ola migratoria hacia Guayaquil, ciudad que creció enormemente debido al aumento de comercio y productividad, pero en la que también surgieron lugares de exclusión social, barrios populares en los que se asentaron los migrantes (Rodríguez Albán, 2006).

Por otro lado, el acceso a la educación favoreció, sobre todo, a los mestizos, quienes encontraron en los puestos que se abrieron en las nuevas instituciones públicas, una oportunidad para negar su pasado, lo que llevó a una ola migratoria hacia Quito, ciudad en la que, igualmente, se gestaron asentamientos marginales. Esto es clave para comprender la obra de Palacio, debido a que permite explicar por qué sus personajes son seres excluidos o marginales.

Según Rodríguez Albán (2006), los personajes marginales o excluidos se aprecian en algunas obras de aquellas épocas, pues son el producto de las olas migratorias que llevan a ver nuevos rostros en las grandes ciudades, es decir, que los indígenas y afros que llegaron y se constituyeron en los marginales ahora son un punto de reflexión literaria.

Esta influencia de las transformaciones sociales promovió una literatura fuertemente imbuida del conflicto social. Así, la generación del 30 constituyó el mayor referente de esta época, ya que sus obras utilizaban como personajes, precisamente, a aquellos marginales y excluidos por el proyecto mestizo de Estado-nación, cuya homogenización significaba el enmascaramiento de algunos pueblos y personas alejadas de los grupos de poder, como los proletarios, montuvios e indígenas.

Influenciado por los conflictos sociales derivados de la desigualdad en la distribución de la riqueza, el realismo social surgió como el medio de denuncia de las condiciones de los obreros. Con temas que abordaban problemas como la explotación, la pobreza y la lucha proletaria, este movimiento atrajo seguidores en los círculos literarios, que veían en la literatura el mejor aliado para hablar por estos excluidos. De aquí y de la mano de Jorge Icaza se derivó el indigenismo, que buscaba denunciar los problemas de la explotación indígena (Robles, 2006).

Por otro lado, no solo los obreros e indígenas eran los excluidos de este proyecto modernizador, sino que, además, 
esta homogenización que exige el Estadonación otorgó el epíteto de otros a algunos grupos como los montuvios. El grupo de Guayaquil se enfocó en describir y hablar sobre ellos, intentó colocarlos en el debate nacional, lograr que los demás conozcan sus costumbres. Es decir que esto constituyó un intento de los escritores guayaquileños por hablar de aquello que había sido ocultado.

En todos estos movimientos es patente que la exclusión se deriva de lo étnico y económico, lo que, evidentemente, es cierto, sin embargo, esto es, precisamente, lo que llevó a Palacio a buscar nuevas temáticas en las que la exclusión es vista desde la esencia misma del orden racional, es decir, la exclusión más allá de lo étnico (Holst, 1998).

De acuerdo con Robles (2006), los cambios suscitados en ese contexto colocaban sobre la mesa dos opciones: Freud, que significaba explorar al individuo moderno ecuatoriano en tanto ser y no colectivo, lo que implicaba no hablar de lo étnico; la otra opción fue Marx, que significaba hablar de los grupos marginados, la desigualdad social y, en definitiva, las condiciones materiales de exclusión. En pocas palabras, el primer camino lleva al vanguardismo y el otro al realismo, criollismo e indigenismo.

El vanguardismo presenta dos visiones importantes para comprender la obra de Palacio. Primero, como afirma Bosi (2002), las vanguardias son producto del avance capitalista, pues plasman la individualidad y libertad que profesa y pide la burguesía, aquella libertad que fue reclamada y reconocida con las revoluciones liberales del siglo XVIII. Sin embargo, en América Latina sucedió algo excepcional, que origina la segunda forma de ver al vanguardismo, y es que, según Schwarz (2002), la región intentó, desde que se independizó, encontrar una identidad propia. En este proceso pudo decantarse por imitar a Europa o construir una identidad propia basada en la diversidad cultural.

Quizás el vanguardismo representó la mejor estrategia para construir el imaginario latinoamericano, puesto que el ideal de libertad y desconocimiento de cánones favorecía a los artistas para que puedan romper sus ataduras con el arte europeo y pudiesen crear según su propio contexto. Prueba de esto es el surgimiento de varios movimientos de vanguardia en los que se buscó dar a luz a la identidad de la región, como el Antropófago en Brasil, el Nadaísta en Colombia y el Tzánzico en Ecuador (Polo, 2010), cuyo mayor interés fue reducir los imaginarios europeos a tal punto que los pudiesen transgredir.

Ahora bien, Palacio es un autor que vivió estas transformaciones de la modernidad en Ecuador y que, al escribir, se decantó por hablar del latinoamericano con libertad, usando a los marginados como personajes para, otorgándoles voz, burlarse de lo normal, es decir, criticar los mismos poderes que criticaron los realistas, pero desde una perspectiva no étnica, debilitando las certezas europeas que fueron impuestas con las transformaciones liberales.

\section{Cuadrado ideológico y análisis del discurso}

Palacio irrumpió en el panorama nacional con su literatura de los entrometidos, debido a que El antropófago cuenta la historia del animal, de aquel ser alejado del orden racional que, por lo tanto, debe ser rechazado. Es decir, los discursos que se encontraban de moda 
en la época en la vivió este autor fueron una enorme influencia en el contenido de su obra. Esto sucedió porque la modernidad, que estaba arraigándose en el imaginario nacional, había promovido la implantación de los ideales europeos que veían en el caníbal una representación del salvaje a ser rechazado (Fernández Retamar, 2004).

El cuento que actúa como el objeto de estudio presenta de forma casi literal esta dicotomía que es propósito de la investigación, pues coloca un personaje que es, textualmente, un caníbal, precisamente, el imaginario que Europa atribuyó a América, por lo que esta obra insinúa que busca hacer una crítica a esa idea y cómo ha funcionado. Además, haber escogido el tema de la antropofagia genera un interés teórico, ya que devorar al otro es una metáfora que explica lo que intentaron hacer las vanguardias latinoamericanas y ecuatorianas: absorber los imaginarios e ideologías implantados por Europa y convertirlos en una nueva identidad que provenga del mismo bárbaro.

En definitiva, El antropófago facilita el análisis discursivo de la dicotomía civilización-barbarie para comprender cómo se ha conformado la sociedad desde la negación. Asimismo, usar un caníbal como personaje principal permite demostrar que la expulsión de lo no-racional crea la cultura dominante; además, que este proceso, a su vez, en Palacio se da desde el punto de vista del bárbaro, demostrando que el dilema de la exclusión es un acto racional que atañe a cualquier identidad; $\mathrm{y}$, por último, que la antropofagia está presente en cualquier formación social como estrategia de poder.

El análisis del discurso es un proceso de reflexión racional que posibilita estudiar el trasfondo de lo que se expresa. En las ideas de Foucault (1970), lo importante de ese universo semántico llamado discurso es lo no dicho, es decir, lo que el discurso oculta, puesto que el enmascaramiento de lo falso o no aceptado es una estrategia esencial en la producción discursiva.

$\mathrm{Al}$ ser la materialidad de las estructuras sociales, el discurso se compone de pequeñas partes conocidas como enunciados, que constituyen sus átomos. Para encontrarlos es preciso ubicar las producciones semánticas, lingüísticas o no, generadas en la sociedad o determinado objeto discursivo. Sin embargo, estas aparecen de forma dispersa y es el papel del analista encontrar las relaciones que las unen para formar y comprender qué ocultan, explicando así el discurso. Entonces, el primer paso en este proceso deductivo fue encontrar lo que Vasilachis (1997) llamó el corpus del texto, el conjunto de enunciados a analizar; acción que se basó en los contenidos asociados a la civilización y la barbarie.

Para determinar cómo funcionan los enunciados y llegar a conclusiones lógicas es preciso un filtro, criterios de clasificación. Aquí es pertinente utilizar el método del cuadrado ideológico de Van Dijk (2005), que consiste en cuatro criterios clave, que son:

- Hacer énfasis en nuestras cosas buenas

- Hacer énfasis en sus cosas malas

- Minimizar sus cosas buenas

- Minimizar nuestras cosas malas

Entonces, una vez encontrado el corpus de enunciados lingüísticos presentes en el cuento, fue conveniente analizarlo de acuerdo con estos parámetros, 
tomando en consideración la posición enunciativa que, en este caso, fue la del bárbaro. Las conclusiones llevarán a comprender quién ha construido el discurso y qué significa el cuento de Palacio.

\section{El giro palaciano y el discurso del otro}

Considerando que el punto de vista toma un giro en la obra de Palacio, la posición enunciativa la tiene el bárbaro, el caníbal, al antropófago, llamado Nico Tiberio, así que los enunciados se clasificaron en el cuadrado ideológico de acuerdo con esta consideración. Pero este giro del punto de enunciación no es gratuito, y es que parece ser que obedece a las intenciones, más o menos conscientes, del autor, puesto que la realidad que vivió es, precisamente, la del cúmulo de bárbaros que iban surgiendo producto de la modernización, ya que mientras mayor modernización se daba, más cerca a Europa estaba América y, por ende, más bárbaros tenía. Aunque es común que el punto de vista se centre en quien representa la civilización y se hable desde allí, Palacio parece intentar meterse en los zapatos de Nico Tiberio a través del estudiante de criminología, personaje encargado de contar la historia y que, se puede asumir, representa la voz del excluido, un excluido que, según se verá, no es exactamente un salvaje, sino un ser humano.

En cuanto al énfasis sobre nuestras cosas buenas, asumiendo que el bárbaro es el nosotros, en un primer momento Palacio nos muestra una prisión con un antropófago que parece estar sufriendo, que ha cometido un acto que es despreciado por todos, pero que, por la misma razón, se convierte en un objeto curioso, algo "raro" que apreciar. Entonces, al describir la dieta de legumbres que le dieron a Nico Tiberio al llegar a la prisión se aprecia cómo la frase: “iPonérseles en la cabeza el martirizar de tal manera a un hombre habituado a servirse viandas sabrosas!" (Palacio, 2013, p. 31) empieza a situar al caníbal en prisión como el bueno, como aquel que no ha hecho nada malo, excepto disfrutar de algo delicioso. Nótese la connotación de la palabra delicioso como un acto de disfrute que no se acerca, en ningún sentido, a ser algo malo.

Otro recurso recurrente que usó el autor en este cuento para hacer énfasis en las cosas buenas de la barbarie fue que el estudiante de criminalística naturaliza constantemente las acciones del antropófago y, como se ha comprendido con Foucault (2002) y Gramsci (1984), lo normal (bueno) se naturaliza, se vuelve común, se asimila y se defiende como la verdad y única visión posible. Esto sucede con frases como "No teniendo nada de fiera, molesta" o "A la final, la culpa no era de él. ¿Qué culpa va a tener! [...] si era hijo de un carnicero y una comadrona" (Palacio, 2013, p. 31).

Este recurso, este uso de la estrategia de poder de la naturalización promueve que en la obra se vea un discurso del bárbaro que se presenta como lo bueno porque es común, atañe a todos y nadie se escapa de sus pasiones animalescas, es decir que el yo (expresado en el caníbal) excluye al otro (expresado en los guardias y quienes lo van a visitar a la prisión).

Pero esto no funciona solo, pues para naturalizar una acción como devorar la cara de un niño, es preciso también hacer énfasis en las cosas malas del otro, y Palacio utiliza también este recurso, puesto que acusa a los otros (los civilizados) de ir a visitarlo solamente para azu- 
zarlo, mientras él se queda quieto, pacífico y, aunque se mencione que pareciera que él esperaba el momento para atacar, nunca lo hace, lo que denota una actitud opuesta a aquella de la que se le acusa; es decir que si el antropófago era el salvaje, el caníbal, el otro, entonces al no actuar como lo que se dice o se imagina que es, hay que molestarlo hasta que se muestre como el bárbaro porque solo así es como el imaginario sobre la barbarie lo ha construido.

Nótese el énfasis que hace el estudiante de criminalística al describir las burlas y provocaciones que la gente que lo visita le hace, pues describe que "han llegado hasta a molestarle, introduciendo por un instante un dedo tembloroso por entre los hierros, pero el antropófago se está quieto, mirando con sus ojos vacíos" (Ibid., p. 30). Luego, acusa de infames a sus compañeros, atribuyéndoles un adjetivo de connotación insultante con el fin de hacer notar que, si el antropófago ataca, será enteramente culpa de ellos, del otro -civilización, pues Nico Tiberio apenas era un "pobre hombre que miraba vagamente y cuya gran cabeza oscilaba como una aguja imantada".

Siguiendo con la lógica de este relato, el estudiante continúa con su estrategia de exclusión y minimiza las cosas malas del antropófago haciendo alusión a que la culpa no era suya sino de la realidad que vivió.

En primera instancia, Nico era oncemesino, algo peligroso, según el mismo narrador, ya que quien vive "por tanto tiempo de sustancias humanas es lógico que sienta más tarde la necesidad de ellas" (Ibid., p. 32). Además, su padre carnicero, que quería que su hijo siguiese sus pasos, y su madre, tendera y comadrona, que quería que fuera médico, murieron, dejándolo huérfano a los diez años, lo que denota que se minimiza la acción del imputado debido a que esta carencia de la familia, aparato ideológico (Althusser, 1989), significa que él no tuvo quién lo inmiscuyera en las ideologías e imaginarios racionales civilizados que hubieran evitado, de alguna manera, que cometiera el acto tan cercano a lo que se creía que era América desde Europa; y lo corrobora el estudiante al mencionar que "Tenemos, pues, al pequeño Nico en absoluta libertad para vivir a su manera, solo a la edad de diez años" (Palacio, 2013, p. 33), es decir que no fue parte de las regulaciones sociales que debieron limitar su "barbarie” y, por lo tanto, se mostró como lo que es, lo que, parece, es un intento de Palacio por demostrar que sin la artificialidad de la sociedad, el ser humano es en realidad, un animal, por consiguiente, esta faceta caníbal es la verdad.

Entonces, cabe una simple pregunta, y es que ¿cómo se puede acusar al antropófago de haber hecho algo malo si, en primera instancia, no fue su culpa y, segundo, solo actuó conforme a la verdad, fuera de la virtualidad social? Es evidente que la respuesta es que no se puede acusarlo de haber hecho algo malo.

Por último, los enunciados inscritos en la minimización de las cosas buenas de los otros se presentan en torno a contrastar lo que comúnmente se acepta como bueno con lo que es malo. Es así que castigar a un criminal es un acto visto con buenos ojos por una sociedad civilizatoria, pero cuando se describe que los guardias de la prisión, sabiendo que el antropófago gusta de la carne, le dan legumbres, entonces se pone en tela de juicio esta bondad, este hacer el bien que es criticado por el estudiante de la siguiente manera: 
Al principio le prescribieron dieta: legumbres y nada más que legumbres; pero había sido de ver la gresca armada. Los vigilantes creyeron que iba a romper los hierros y comérselos a toditos. iY se lo merecían los muy crueles! iPonérseles en la cabeza el martirizar de tal manera a un hombre habituado a servirse viandas sabrosas! (Ibid., p. 31).

Del mismo modo, cuando se describe que los vecinos detienen a Nico Tiberio mientras devoraba la cara de su hijo, en una primera mirada se puede creer que fueron héroes que detuvieron un acto fuera del orden social, pero luego "le dieron de garrotazos, con una crueldad sin límites, le ataron, cuando le vieron tendido y sin conocimiento; le entregaron a la policía... iAhora se vengarán de él!" (Ibid., p. 34), lo que minimiza el buen acto de los civilizados y los coloca en la misma situación que ellos acusan, la de salvajes y bárbaros.

Por otro lado, en la misma escena, el estudiante describe lo siguiente: "Y como no hay en la vida cosa cabal, vinieron los vecinos a arrancarle de su abstraído entretenimiento" (Ibid., p. 34). Es evidente que el uso de la palabra arrancar sirve de herramienta al autor para demostrar su desaprobación, ya que esta palabra contiene un sentido negativo que se refiere a sacar algo con violencia.

En todo caso, esta escena corrobora que la verdad se construye de acuerdo con el imaginario y la ideología de quien actúa, lo que significa que los actos no son buenos o malos en sí mismos; y, así como la sociedad que está fuera de la cárcel en la que se encuentra Nico Tiberio convino que castigarlo duramente es lo correcto, el estudiante, el enunciante, sostiene que ese acto, en realidad, es despreciable.
Es evidente, por tanto, que aun cuando Palacio intentara criticar las bases de la civilización cambiando el punto de enunciación y colocándolo en el bárbaro, terminó por utilizar las mismas estrategias discursivas de las que hablaba Foucault (1970), desde la formación de una verdad que se quiso naturalizar hasta la negación del otro y su enmascaramiento.

Quizás la frase que resume la obra es aquella con la que cierra, que reza de la siguiente manera: "Si yo creyera a los imbéciles tendría que decir: Tiberio (padre) es como quien se come lo que crea" (Palacio, 2013, p. 34). Esto porque al analizarla se comprende, precisamente, los rasgos que reveló el inconsciente del texto y a los cuales se ha llegado a través del análisis discursivo.

Para comprender este enunciado es preciso asumir la antropofagia como estrategia contrahegemónica (Fernández Retamar, 2004), puesto que se refiere a devorar algo para luego devolver una síntesis entre lo devorado y el devorador. Es decir, que cuando la exclusión proviene desde el lado excluido de los imaginarios e ideologías hegemónicos, entonces es una estrategia antropofágica para situar su verdad en las relaciones de poder.

Con base en esto, surgieron ciertas preguntas para analizar la frase en relación al contenido del texto. Primero, ¿quiénes son los imbéciles? Son quienes no han asumido al otro como parte de sí mismos, quienes se niegan a aceptar que para identificarse hay que devorar al otro, en el sentido que le dio Fernández Retamar al término. Ahora, cqué es lo que el antropófago crea? Al otro, el otro es su hijo al que devora, así que el civilizado no puede existir sin el bárbaro y viceversa, lo que significa que castigar el acto de Nico Tiberio es, irónicamente, una negación 
del mismo yo, de allí que el estudiante les atribuya el epíteto de imbéciles.

\section{Conclusiones}

El antropófago, el caníbal, es el animal que el orden civilizatorio busca excluir, pero no negar, ya que es un mal necesario, de lo contrario, no podría contraponer sus imaginarios para darles validez (Eco, 2011) porque la verdad discursiva solo existe en la medida en que se crea su falsedad (Foucault, 1970). De aquí se derivó la dicotomía civilizaciónbarbarie, que sirvió para que el imaginario de la racionalidad occidental europea se posicione frente a la identidad latinoamericana y se constituya en hegemónico. Pero, en una mirada más allá de los intereses del orden occidental, se descubre que el dilema de la exclusión no es solo estrategia colonizadora y hegemónica, sino que es la forma en la que la identidad humana se construye. Por tal motivo, no resulta una sorpresa que el cuento de $\mathrm{Pa}$ lacio plantee una mirada desde el otro de Europa, desde el animal, con la intención de poner en jaque las bases racionales y utilizar estrategias contrahegemónicas, lo que se deriva, precisamente de la hegemonía de los discursos occidentalizados. Aquí la deducción más acertada es que se corrobora que la construcción de imaginarios que se posicionan de acuerdo con los discursos del grupo que los origina atañe tanto al marginador como al marginado.

Palacio utiliza esta táctica discursiva y le da la vuelta, convirtiéndola en un acto contrahegemónico que afirma la ve- racidad de lo falso en el escenario social, lo que crea una ruptura que abre espacios de debate para poner en duda las certezas civilizatorias. Es por esto que se vale de la antropofagia, pues así logra demostrar que, en el medio social, los imaginarios e ideologías se devoran constantemente para conseguir institucionalizarse, ya sea que provengan desde el discurso imperante o del subordinado.

Si bien es cierto que ambas partes la aceptada por la sociedad y la excluidautilizan el rechazo del otro como medio para afianzar su identidad, existen matices en cuanto a lo que consiguen y qué tan difícil es el camino. Evidentemente, si la exclusión proviene del orden imperante, este solo legitimará a quienes piensen como él desea, es decir, que aquí el esfuerzo consiste en mantenerse; sin embargo, si el rechazo del otro nace del excluido, el marginal o bárbaro, entonces el esfuerzo se da por ser reconocido, lo que constituye una lucha desigual, aunque se usen las mismas armas.

Asumiendo como axioma que la literatura surge de un medio social y, por tanto, lo representa de forma explícita o implícita, la realidad ecuatoriana de inicios del siglo XX se ve reflejada en el cuento El antropófago, lo que se aprecia porque el animal, el caníbal, es el otro europeo, y es él el rechazado. Esto se resume en que la modernización de aquellos años afianzó las luchas simbólicas entre lo europeo y lo latinoamericano, creando esta preocupación en Palacio, que tomó una clara postura a favor del bárbaro, con la intención de excluir, pero, desde el otro lado de la historia: el del vencido. 


\section{BibLiOgRAFía}

Acosta Espinosa, Alberto J. (2006). Breve historia económica del Ecuador. Quito: Corporación Editora Nacional.

Almazán Gómez, Adrián. (2016). ¿Ruralidad o barbarie? Oxímora: Revista internacional de ética y política, 8, 148-160.

Ayala Mora, Enrique A. (2008). Resumen de historia del Ecuador. Quito: Corporación Editora Nacional.

Baeza Rodríguez, Manuel A. (2011). Elementos básicos de una teoría fenomenológica de los imaginarios sociales. En Jesús A.Valero Matas, Juan Romay Coca, Francesca Randazzo Eisemann, y Juan L. Pintos de Cea Naharro. (Eds.). Nuevas posibilidades de los imaginarios sociales (pp. 31 - 42). Badajoz: Asociación Cultural Tremn.

Castoriadis, Cornelius. (2007). La institución imaginaria de la sociedad. Buenos Aires: Tusquets.

Cevallos González, Santiago. (2006). Propuestas literarias modernas: la incorporación de otros lenguajes en las narrativas icaciana y palaciana. Kipus: revista andina de letras (20), 5 - 27.

Cuadrada Majó, María C. (2015). Marginalidad y otredad en Cataluña (siglos XIV-XVI). La España Medieval, 38 (1), 57-97.

Eco, Umberto. (2011). Construir al enemigo. Titivillus. Recuperado de: http://www.kasalpopular.net/wpcontent/uploads/2016/09/uecaeyooee.pdf

Fernández Retamar, Roberto. (2004). Calibán. Buenos Aires: CLACSO.

Foucault, Paul-Michel. (1970). La arqueología del saber. Madrid: Siglo XXI.

Foucault, Paul-Michel. (1980). Microfísica del poder. Madrid: La Piqueta.

Foucault, Paul-Michel. (2002). El orden del discurso. Barcelona: Fábula.

Friese, Heidrun. (2004). La otredad de Europa. Política y Sociedad, 99-112.

González Stephan, Beatriz. (1996). El cuerpo salvaje de la nación: ciudadanías desplazadas (Siglo XXI). Kipus: Revista Andina de Letras (5), 4-18.

Gramsci, Antonio. (1984). Cuadernos de la cárcel. México D. F.: Era.

Grijalva, Juan Carlos. (1997). Civilización y barbarie en Las Catilinarias de Juan Montalvo (Tesis de maestría). Universidad Andina Simón Bolívar, Quito.

Holst Molestina, Gilda. (1998). Pablo Palacio y un largo, inmenso y razonado desarreglo de todos los sentidos. Kipus: revista andina de letras (8), 59-75.

Lacan, Jacques. (1996). El estadio del espejo como formador de la función del yo, tal y como se nos revela en la experiencia psicoanalítica. Recuperado de: https:/www.bibliopsi.org/docs/lacan/33\%20Los\%20Escritos\%20de\%20Jacques\%20Lacan.pdf

Martín, Carlos. (2010). La conquista del "otro": en los filmes Aguirre la ira de Dios y Fitzcarraldo de W. Herzog. Resistencia: revista de los estudiantes de la Universidad Andina Simón Bolívar (2), 47-50.

Modonesi, Massimo. (2010). Subalternidad, antagonismo, autonomía: Marxismo y subjetivación política. Buenos Aires: CLACSO.

Nietzsche, Friedrich W. (1970). Sobre verdad y mentira en sentido extramoral. Buenos Aires: Prestigio.

Nuzzo, Enrico. (2003). Figuras de la barbarie: lugares y tiempos de la barbarie en Vico. Cuadernos sobre Vico 15-16, 151 162.

Ozoukouo Léa, N’drin. (2013). La dualidad Civilización/Barbarie en la selva de José Eustasio Rivera: "La Vorágine", los Ilanos de Rómulo Gallegos: "Doña Bárbara" y las pampas de Ricardo Guiraldes: "Don Segundo Sombra" (Tesis de doctorado). Universidad Autónoma de Barcelona, Barcelona. 
Palacio Suárez, Pablo A. (2013). El antropófago. En Patricio Herrera Crespo. (Ed.). Pablo Palacio: Obras Completas (pp. 30-34). Quito: Casa de la Cultura Ecuatoriana Benjamín Carrión.

Palacios, María Á. E. (2002). La figura del mal en la narrativa de Pablo Palacio. Kipus: Revista Andina de Letras (14), $75-$ 92.

Parrilla Rubio, María V. (2007). Tan otro que ni otredad posee: eso que llaman el animal. Thémata: Revista de Filosofía (39), 71-78.

Polo Bonilla, Rafael. (2010). Crítica y modernidad. De la emergencia Tzánzica al Frente Cultural. Quito en la década de los sesenta. En Felipe Burbano de Lara.(Ed.). Transiciones y rupturas: El Ecuador en la segunda mitad del siglo XX (pp. 341-376). Quito: FLACSO.

Re, Lucia. (2012). 'Barbari civilizzatissimi': Marinetti and the futurist myth of barbarism. Journal of modern italian studies 17, 350-368.

Rea, Andrea. (2006). La europeización de la política migratoria y la transformación de la otredad. Revista española de investigaciones sociológicas (116), 157-183.

Robles, Humberto. (2006). La noción de vanguardia en el Ecuador. Quito: Corporación Editora Nacional.

Rodríguez Albán, Martha. (2006). Narradores ecuatorianos de la década del 1950: poéticas para la lectura de modernidades periféricas (Tesis de maestría). Universidad Andina Simón Bolívar, Quito.

Rodríguez Jiménez, Olga Marta. (2014). La naturaleza y la otredad humana en Nuestra América y otros textos de José Martí. Revista Estudios (28), 2-14.

Silva Téllez, Armando. (2006). Imaginarios urbanos. Bogotá: Nomos.

Todorov, Tzvetan. (1998). La conquista de América: el problema del otro. Madrid: Siglo XXI.

Van Dijk, Teun. (2003). Ideología y discurso: Una introducción multidisciplinaria. Barcelona: Ariel.

Van Dijk, Teun. (2005). Política, ideología y discurso. Quórum Académico, 15-47. 